\title{
Characterization of High Density Lipoproteins in Patients Heterozygous for Tangier Disease
}

\author{
Gerd Assmann, Otto Simantke, Hans-Eckart Schaefer, and Elanne \\ SMOOTZ, Abteilung für Klinische Chemie und Zentrallaboratorium \\ der Kliniken der Universität Köln, und Pathologisches Institut \\ der Universität Köln, 5 Köln 41, West Germany
}

\begin{abstract}
A B S T RAC T In this study a large family group affected with Tangier disease has been investigated. Besides two homozygous propositi, several heterozygous patients have been identified on the basis of quantitative measurements of high density lipoproteins and their constitutive polypeptides. By a variety of quantitative immunological methods, such as one-dimensional Laurell electrophoresis, two-dimensional immunoeletrophoresis, and double-antibody radioimmunoassay, the total amount of apoprotein A-I and apoprotein A-II contained in the serum of heterozygous patients and the distribution of these $A$ apoproteins among serum lipoproteins have been determined. The molar ratio of apoprotein A-I and apoprotein A-II contained in high density lipoproteins of heterozygous patients did not significantly differ from that of control preparations, although the total mass of high density lipoproteins was reduced by approximately $50 \%$. The elution profile of high density lipoproteins from agarose columns and their morphological appearance, as ascertained by electron microscopy, were similar to control preparations. In addition to the quantitative alterations of serum lipoproteins, lipid storage in histiocytes of the rectal mucosa obtained from heterozygous patients has been documented. It is concluded that patients heterozygous for Tangier disease have normal high density lipoproteins in circulation, the total mass of which is reduced by approximately $50 \%$.
\end{abstract}

\section{INTRODUCTION}

We have previously determined that normal high density lipoproteins (HDL) ${ }^{1}$, as defined by polypeptide composition and morphological appearance, are absent

Received for publication 3 March 1977 and in revised form 15 June 1977.

${ }^{1}$ Abbreviations used in this paper: Apo A-I, apoprotein A-I; Apo A-II, apoprotein A-II; HDL, high density lipoproteins; LDL, low density lipoproteins; VLDL, very low density lipoproteins. from the plasma of patients homozygous for Tangier disease, and that only trace quantities of the major HDL apoproteins, apoprotein A-I (Apo A-I) and apoprotein A-II (Apo A-II), can be detected in their plasma $(1,2)$. Instead, an abnormal lipoprotein, which contains only Apo A-II as protein constituent, has been identified and characterized (2). To understand further the nature of the biochemical defect in Tangier disease and the metabolic role of HDL in plasma, we have undertaken a study of the macromolecular composition of HDL in members of one large family group. The study was designed first to identify heterozygous patients in a survey of a family affected with Tangier disease, and second to characterize their HDL. The results of this biochemical and genetic investigation are the subject of this report.

\section{METHODS}

Patients. The clinical and biochemical findings of the propositi (E. G., J. S.) of this family group have previously been reported in detail (1-4). The family originated in an area of geographical isolation near the city of Cochem at the Mosel River, and approximately $90 \%$ of the close and distant relatives of the propositi now live in eight adjacent villages within a total area of about 50 square miles. Comprehensive pedigree information extending several generations back was obtained from written records, i.e. church books, the earliest dating back to 1640 ; however, between 1640 and 1676 the family data were incomplete.

Relatives. Fasting blood samples were obtained from 143 subjects related to the propositi. These subjects were subdivided into three groups: (a) 59 close relatives, including parents, siblings of parents, and offspring; $(b) 69$ distant relatives, including offspring of siblings of grandparents and greatgrandparents; and (c) 15 spouses of relatives. Fasting blood samples were repeatedly obtained, as many as 10 times, from obligate heterozygous patients (children and parents of propositi), and certain relatives who, on the basis of low HDL cholesterol and low serum Apo A-I levels at the original sampling, were suspected to be heterozygous for Tangier disease.

Controls. Serum samples from 148 apparently healthy subjects (hospital employees and employees of a pharmaceutical company in Köln) and 989 hospital inpatients (depart- 
ments of internal medicine, surgery, and dermatology) were separately analyzed as controls. Out of the 989 hospital inpatients, a subgroup of 561 normolipidemic subjects (age-adjusted for cholesterol and triglyceride values) have been separately investigated.

Healthy subjects were ambulatory, had no known family history of hyperlipidemia or diabetes mellitus, and had normal liver function as assessed by determination of aspartate and alanine amino-transferase, alkaline phosphatase, and $\mathrm{L}-\boldsymbol{\gamma}$ glutamyl-transferase. Although most of the control patients (estimated 95\%) were fasting at the time of sampling, food intake in some patients might have influenced HDL cholesterol values. To evaluate this possibility, serum of 20 normal volunteers was obtained before and $3 \mathrm{~h}$ after breakfast, which consisted of $800 \mathrm{cal}$ and was chosen to contain either 560 calories of carbohydrate or 560 calories of fat.

Blood samples. 20-100-ml samples of antecubital vein blood were collected on the same day from 143 relatives. The sera were obtained by centrifugation at $10^{\circ} \mathrm{C}$ within $4 \mathrm{~h}$ and were processed for cholesterol, triglyceride, HDL cholesterol, and serum Apo A-I within $12 \mathrm{~h}$ after sampling. This approach guaranteed optimal conditions of standarization and reproducibility of analytical methods. To confirm the genetic relationship of individuals, serological typing of blood and tissue antigens was performed on all samples ${ }^{2}$.

Lipid and lipoprotein analyses. Serum samples were enzymatically analyzed for cholesterol and triglyceride on a twochannel AutoAnalyzer (Technicon Instruments Corp., Tarrytown, N. Y.) as described $(5,6)$. The coefficient of variation was less than $1 \%$, and accuracy was within $3 \%$ of the target value for cholesterol analysis; whereas for triglyceride analysis, the coefficient of variation was less than $3 \%$ and accuracy was within $5 \%$. Very low density lipoproteins (VLDL) and low density lipoproteins (LDL) were precipitated from a l-ml aliquot of serum by the addition of $50 \mu \mathrm{l}$ of $2 \mathrm{M} \mathrm{MgCl}_{2}$ and $50 \mu \mathrm{l}$ of dextran sulfate 500, 20 g/liter (Pharmacia Fine Chemicals, Inc. Uppsala, Sweden), (7), and HDL cholesterol determination was performed on the supernatant fraction by the enzymatic cholesterol method.

The validity of this method for HDL cholesterol determination was evaluated in the following ways: (a) In 150 control sera, lipoproteins were isolated as specifically outlined by the Lipid Research Clinic study protocol (8), except that Apo Bcontaining lipoproteins (LDL, lipoprotein[a]) of the 1.006 infranate were precipitated by the $\mathrm{MgCl}_{2}$-dextran sulfate procedure, followed by enzymatic cholesterol determination of the supernate. Comparison of HDL cholesterol values obtained by the different methods revealed that the results were identical within analytical error alone (correlation coefficient 0.99 ). (b) With 100 further control sera, single fractionation was performed at $d=1.063 \mathrm{~g} / \mathrm{ml} \mathrm{KBr}(48 \mathrm{~h}$ at $50,000 \mathrm{rpm} ; 50 \mathrm{Ti}$ rotor; Beckman Instruments, Inc., Fullerton, Calif.), and the cholesterol in the $d>1.063 \mathrm{~g} / \mathrm{ml}$ isolate was compared with values obtained by the precipitation method. In these experiments, no significant difference in the cholesterol values obtained by the different analytical methods was observed (correlation coefficient 0.95). (c) The purity of HDL obtained by the precipitation technique was qualitatively assessed in all specimens by agarose electrophoresis of the supernate (pre-prepared agarose gels; Corning-EEl, Halstead, Essex, England). As determined by the addition of increasing amounts of isolated HDL to fresh serum, recovery of HDL was complete up to concentrations of $150 \mathrm{mg} / \mathrm{dl}$. (d) The serum Apo A-I content was measured in 20 specimens before and after precipitation

${ }^{2}$ Analyses of blood and tissue antigens of relatives of propositi were kindly performed by Professor Dr. Ch. Rittner and Dr. P. Hanfland, Kliniken der Universität Bonn. of VLDL and LDL by radioimmunoassay (1) and was found to be almost identical (correlation coefficient 0.96 ). This result excluded the possibility that, under the experimental conditions chosen, a significant part of the HDL coprecipitated and escaped determination. Quantitation of Apo A-I was performed by double-antibody radioimmunoassay (1) using the original, nondelipidated serum as antigen source. Inasmuch as only $30 \%$ of the Apo A-I present in fresh serum can be identified by our radioimmunoassay procedure without prior delipidation, absolute serum Apo A-I values have been calculated by extrapolation (factor 3.3). It is realized, however, that the degree of immunoreactivity of Apo A-I in both native and partially delipidated lipoproteins may not be identical from sample to sample, and that this approach may only serve to obtain approximate values.

Quantitation and composition of HDL in heterozygotes. Further analysis of HDL (see below) was performed in the following patients: eight obligate heterozygous patients (parents and children of propositi) and five presumed heterozygous patients (see Results). The following analyses were performed for all heterozygous patients and 10 normolipidemic controls: (a) quantitation of $\mathrm{A}$ apoproteins in serum by twodimensional immunoelectrophoresis. Monospecific antisera for Apo A-I and Apo A-II were raised as previously described (1). An antiserum that contained antibodies to both Apo A-I and Apo A-II was obtained commercially (Behring-Werke, AG., Marburg, West Germany). These antisera were utilized to quantitate the $A$ apoproteins by two-dimensional immunoelectrophoresis (1) in whole serum. At the end of the first electrophoresis, two strips of identical size (each $50 \times 5 \mathrm{~mm}$ and corresponding to $1 \mu$ in original serum) were removed from one microscope slide and separately analyzed for the presence of Apo A-I and Apo A-II. This approach guaranteed that identical amounts of serum were analyzed for their apoprotein content, thus facilitating the accurate determination of Apo A-I/Apo A-II ratios and absolute quantities in serum. Standard curves were obtained with two reference serum samples and two HDL samples (isolated by ultracentrifugation) in which the precise amounts of Apo A-I and Apo A-II were determined by radioimmunoassay of delipidated aliquots (1). The reference samples were stored at $4^{\circ} \mathrm{C}$ and used over a period of 2 mo. There was a linear relationship between the protein concentration of $A$ apoproteins contained in serum or HDL samples and the areas under the immunoprecipitin arcs. The between-assay coefficients of variation over a period of 2 mo for the Apo A-I/Apo A-II ratio of the reference sera and HDL standards were $3 \%$ and $4 \%$, respectively. (b) Quantitation of A apoproteins by Laurell electrophoresis: $1 \mu \mathrm{l}$ of standard or sample, properly diluted with buffer, was applied to the electroimmunoassay plate. A field strength of $10 \mathrm{~V} / \mathrm{cm}^{-1}$ was applied to the plate for $10 \mathrm{~h}$. Antisera, serum standards, and HDL standards were those described for the double immunoelectrophoresis procedure. For simplicity, only undelipidated sera of patients were analyzed for their apoprotein content. The between-assay coefficients of variation over a period of $2 \mathrm{mo}$ for the Apo A-I/Apo A-II ratio of the serum and HDL standard were 4 and 5\%, respectively. (c) Quantitation of A apoproteins in Apo HDL by radioimmunoassay (1). HDL was isolated by ultracentrifugation $(1.063-1.21 \mathrm{~g} / \mathrm{ml} \mathrm{KBr}$ ) and delipidated by chloroform-methanol extraction (10). Apoproteins were solubilized in $0.05 \mathrm{M} \mathrm{NH}_{4} \mathrm{HCO}_{3}, \mathrm{pH}$ 8.6, and Apo A-I and Apo A-II concentrations were determined by double-antibody radioimmunoassay (1). Protein concentrations of apoproteins were determined by the method of Lowry et al. (11) using bovine serum albumin as standard. Aliquots of apoproteins were kept

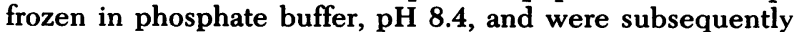
used as quantitative standards for the assays of unknowns. (d) The ratio of Apo A-I to Apo A-II was also qualitatively 
assessed by sodium dodecyl sulphate polyacrylamide electrophoresis (12) of HDL as isolated by agarose column chromatography (see below).

Analysis of HDL by agarose column chromatography. 10 $\mathrm{ml}$ of fresh serum obtained from heterozygous patients and controls were adjusted to $d=1.21 \mathrm{~g} / \mathrm{ml} \mathrm{KBr}$ and spun at 50,000 $\mathrm{rpm}$, using a $50 \mathrm{Ti}$ rotor, for $48 \mathrm{~h}\left(6.5 \times 10^{8} \mathrm{~g}\right.$-min $)$ in the preparative ultracentrifuge (Beckman Instruments, Inc.). After ultracentrifugation, $2.2 \mathrm{ml}$ of the top layer were quantitatively applied to a column of Sepharose 6B (Pharmacia Fine Chemicals, Inc.; column size $200 \times 2 \mathrm{~cm}$ ), equilibrated in $0.9 \%$ $\mathrm{NaCl}, 0.05 \mathrm{M} \mathrm{NH}_{4} \mathrm{HCO}_{3}, 0.01 \%$ EDTA, and $0.01 \% \mathrm{NaN}_{3}$, $\mathrm{pH}$ 8.0. The column effluent was monitored at $280 \mathrm{~nm}$. The presence of $\mathrm{A}$ apoproteins in column fractions was qualitatively assessed by double-immunodiffusion utilizing an antiserum to HDL apoproteins. Column fractions containing A antigenicity were further investigated for the relative distribution of Apo A-I and Apo A-II by sodium dodecyl sulphate polyacrylamide electrophoresis. Cholesterol and triglyceride analyses of column fractions corresponding to VLDL, LDL, and HDL were made on pooled lipoprotein samples which had been concentrated in ultrafiltration cells (Amicon Corp., Lexington, Mass.).

Electron microscopy of HDL. HDL from patients heterozygous for Tangier disease and from controls was prepared by ultracentrifugation $(1.063-1.21 \mathrm{~g} / \mathrm{ml} \mathrm{KBr}$ ) and dialyzed against $100 \mathrm{vol}$ of $0.05 \mathrm{M} \mathrm{NH}_{4} \mathrm{HCO}_{3}, \mathrm{pH}$ 8.6. These preparations were applied to Pioloform-coated copper grids (WackerChemie, GmbH, Burghausen, West Germany) and were negatively stained with $5 \%$ ammonium molybdate solution.

Tissue specimens. Histological and ultrastructural studies were made on rectal mucosa biopsies obtained from the following patients: $(a)$ five patients who, on the basis of biochemical analyses, were suspected to be heterozygous for Tangier disease, $(b)$ the mother of the propositus (obligate heterozygote), $(c)$ one unaffected close relative, and $(d)$ two non-related patients with familial type $V$ hyperlipoproteinemia. The tissue was immediately fixed for $2 \mathrm{~h}$ with $2.5 \%$ glutaraldehyde in $0.1 \mathrm{M}$ phosphate buffer, $\mathrm{pH} 7.2$, washed in the same buffer containing $7 \%$ sucrose, and post-fixed in $2 \%$ osmium tetroxide, phosphate-buffered to $\mathrm{pH}$ 7.2. Semifine and thin sections obtained from material embedded in Epon 812 (Shell Chemical Co., Div. of Shell Oil Co., New York) were stained for light and electron microscopy by the usual procedures.

For the visualization of lipids, $6-\mu \mathrm{m}$ thick cryostate sections were cut from glutaraldehyde-fixed tissue, immersed overnight in a solution of $1 \%$ gum arabicum and $0,88 \mathrm{M}$ sucrose. Sections were stained for lipids by an alcoholic Sudan black B-solution (General Aniline \& Film Corp., New York) containing horseradish peroxidase to prevent nonspecific staining due to endogenous peroxidase (13). The presence of birefringent lipids was examined in unstained serial sections or in sections exposed to nuclear stains (e.g., hematoxylin or Feulgen's reaction). Birefringence was studied under planepolarized light at room temperature and upon heating to $60^{\circ} \mathrm{C}$. To visualize histiocytes further, sections were incubated for the histochemical demonstration of acid phosphatase using the hexazonium method of Barka and Anderson (14). Kaiser's glycerol gelatine (E. Merck, Darmstadt, West Germany) served as a mounting medium in all staining procedures mentioned above. Other frozen sections were stained with hematoxylin eosin, Alcian blue ( $\mathrm{pH} 2.5$ ), periodic acid-Schiff, and Giesma's stain. Unstained sections were studied for autofluorescence by epi- and by dia-illumination with ultraviolet light. Those sections had been dehydrated in ethanol, cleared in xylene, and mounted in Eukitt (Kindler, Freiburg, West Germany).

Other methods. Laboratory data were evaluated using the
Statistical Package for Social Sciences program of Control Data Corporation, St. Paul, Minn.

\section{RESULTS}

Study of the kindred. The propositi are two of three children born to parents of German ancestry, both of whose families have lived at the Mosel River for several generations. The mother and father are both $79 \mathrm{yr}$ of age and in good health. Antecedents of the present family have been traced back to 1640; analysis of the ancestry revealed consanguinity (Fig. 1).

The relationship of HDL cholesterol to serum Apo A-I concentrations among relatives is illustrated in Fig. 2. Total HDL cholesterol levels were correlated with serum Apo A-I concentrations in both male $(r=0.77)$ and female $(r=0.70)$ relatives. A number of relatives were found to have both low HDL cholesterol and Apo A-I concentrations; levels in children and parents of propositi ranged from 27 to $39 \mathrm{mg} / \mathrm{dl}$ for HDL cholesterol, and from 44 to $70 \mathrm{mg} / \mathrm{dl}$ for serum Apo A-I, respectively. Among the obligate heterozygous patients, the mother of the propositi exhibited the highest HDL cholesterol (39 mg/dl) and serum Apo A-I levels $(70 \mathrm{mg} / \mathrm{dl})$. Inspection of the data in Fig. 2 reveals that definite recognition of heterozygous patients on the basis of "abnormally low" Apo A-I values alone or in combination with "abnormally low" HDL cholesterol levels might be difficult to establish. Considerable overlap in both parameters occurred between patients considered normal or abnormally low. The reason for this overlap might be twofold: the radioimmunoassay determination of Apo A-I in nondelipidated serum might not provide enough accuracy, and HDL cholesterol and Apo A-I concentrations are subject to influence by hormones, age, nutrition, hyperlipidemia, and possibly other variables (15), thus theoretically providing only crude parameters for arbitrary selection of Tangier heterozygotes. Despite these considerations, an attempt was made to establish whether or not heterozygotes could be identified among relatives of the propositi on the basis of percentile cutoff points for Apo A-I and (or) HDL cholesterol as determined in a control population. Two control groups (989 hospital in-patients and 148 normal volunteers) were separately analyzed for one or both parameters.

HDL cholesterol concentrations in controls. (a) Effect of nutrition. The HDL cholesterol concentrations measured in 20 normal volunteers before and $3 \mathrm{~h}$ after breakfast (fat or carbohydrate feeding) were either identical or differed by $\pm 1 \mathrm{mg} / \mathrm{dl}$. These data are in accord with previous observations $(16,17)$, that food ingestion does not significantly affect HDL cholesterol levels in normal subjects. (b) Effect of sex and age. In the two control groups, women had significantly higher mean HDL values $(52.2-52.8 \mathrm{mg} / \mathrm{dl})$ than men $(45.5-$ 


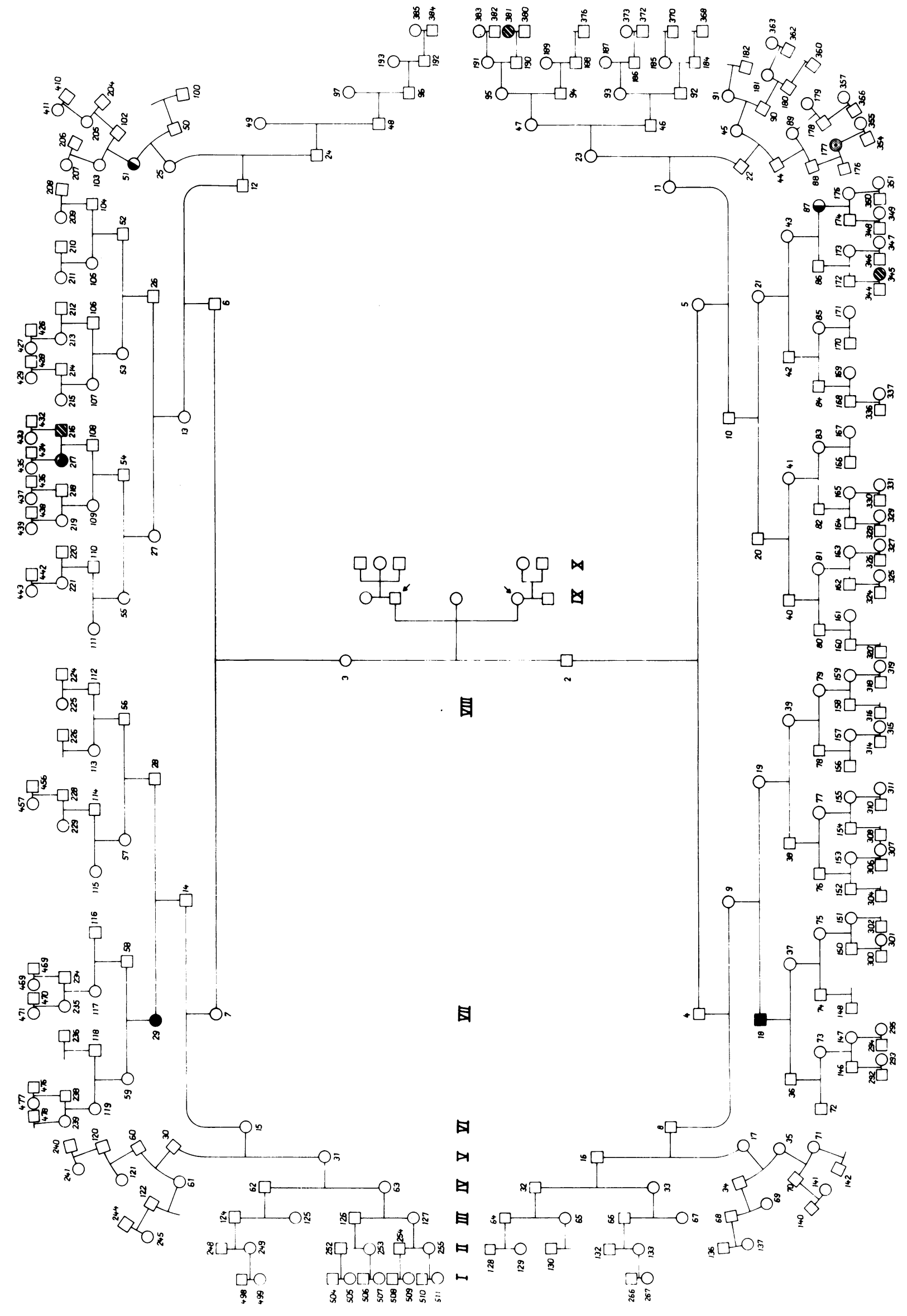


$46.9 \mathrm{mg} / \mathrm{dl})$. The fifth and tenth percentile cutoffs for HDL cholesterol in the control groups are shown in Table I. The mean values for either sex are in close agreement with those reported by others $(15,17,18)$ using different methods of isolation or determination. The mean HDL cholesterol concentration obtained for each sex in seven different age groups among hospital in-patients was not statistically significant.

Serum Apo A-I concentrations in controls. Table II presents the serum Apo A-I concentrations of normolipidemic volunteers as determined by double-antibody radioimmunoassay of fresh serum. The absolute values obtained are similar to those previously determined in delipidated serum (1). The sex difference observed for HDL cholesterol could also be demonstrated for serum Apo A-I concentrations, and the absolute values equal those determined by Albers et al. (15) using an immunodiffusion assay procedure. The possible effects of age are suspected to be minor (15) and have not been investigated.

Identification of heterozygotes. Inasmuch as among distant relatives only a few subjects were found to have low HDL cholesterol and serum Apo A-I values, further analysis was limited to close relatives. A pedigree of close relatives has been constructed (Fig. 3) in which those relatives were provisionally considered heterozygous whose serum Apo A-I levels were lower than the fifth percentile cutoffs of the control group of normolipidemic volunteers (Table II; Apo A-I: $82 \mathrm{mg} / \mathrm{dl}$ in females; $77 \mathrm{mg} / \mathrm{dl}$ in males). For most of the patients selected by these criteria, HDL cholesterol values were likewise below the fifth percentile cutoffs of the controls (Table I; HDL cholesterol: $33 \mathrm{mg} / \mathrm{dl}$ in females; $28 \mathrm{mg} / \mathrm{dl}$ in males), and, with the exception of three females (HDL cholesterol 38, 39, $40 \mathrm{mg} / \mathrm{dl}$ ) and four males (HDL cholesterol 32, 32, 32, $35 \mathrm{mg} / \mathrm{dl}$ ), HDL cholesterols for those subjects in question were within the tenth percentile cutoffs of the controls (Table I; HDL cholesterol: $36 \mathrm{mg} / \mathrm{dl}$ in females; $31 \mathrm{mg} / \mathrm{dl}$ in males). In this context, it appears noteworthy that the sister of the propositi takes oral contraceptives; repeated analyses over a 12 -mo period of the HDL cholesterol of the mother and sister of the propositi showed a variation between 27 and 41 and 29 and $42 \mathrm{mg} / \mathrm{dl}$, respectively. This considerable variability of HDL cholesterol values in heterozygotes has been previously noted by Fredrickson et al. $(17,19)$ and sheds further

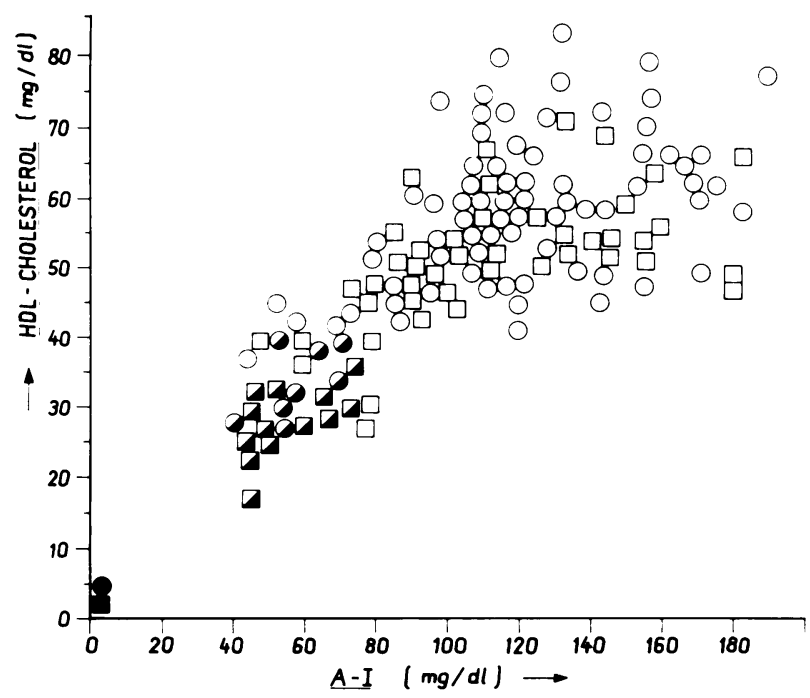

Figure 2 Correlation of HDL cholesterol and serum Apo A-I levels in the affected population (close and distant relatives). HDL cholesterol values were determined enzymatically in serum after $\mathrm{MgCl}_{2}$-dextran sulfate precipitation of Apo B-containing lipoproteins; apparent Apo A-I values were determined by radioimmunoassay using fresh sera without prior delipidation, absolute serum Apo A-I values were calculated by extrapolation of apparent values (factor 3.3; see Methods). Symbols: $\square$ male; $\bigcirc$ female; $\square$ homozygous propositi: $\square \square$ close relatives who were arbitrarily considered heterozygous for Tangier disease on the basis of 5 th percentile cutoffs for serum apoprotein A-I concentrations of controls (see also Table II and Fig. 3). Those individuals who are at or below the 5th percentile Apo A-I cutoffs of controls, but not marked as heterozygous, are distant relatives (not further investigated). Fasting serum cholesterol and serum triglyceride concentrations were also determined in each individual. Complete data available upon request

light on the problem of the predictability of phenotypes by arbitrary cutoff points.

To obtain further support for the validity of the assignment as heterozygous, a specific search for tissue storage of lipids in several of the presumed heterozygotes, one obligate heterozygote, and one non-affected relative (Fig. 3, pedigree numbers: IX $8, \mathrm{X} 3, \mathrm{X} \mathrm{4}, \mathrm{X} 5$, VIII 11, IX 26, IX 35) was undertaken. Since abundant foam cells can be detected in the rectal mucosa of homozygous patients $(3,4)$, rectal biopsy specimens were considered as a convenient source for tissue analysis. Without exception, lipid deposits could be de-

Figure 1 Pedigree of the S. family. The proband, patient J. S., and his homozygous sister, E. G., are marked by an arrow. All those in generation I-VII deceased. Symbols 18 29; 51 ( 87; (๑) 177 (2) 17 ; and $\oslash 216 \oslash 345 \oslash 381$ refer to sibships in the ancestry leading to consanguinity of parents of propositi. Years of birth: individuals 2,3: 1897, 4-7: 1847-1857; 8-15: 1812-1834; 16-31: 1765-1805; 32-63: 1724-1780; 64-127: 1690-1751; 128-255: 1661-1727; 256-511: 1640-1676 (incomplete); complete pedigree data (name, date of birth, date of death) are available upon request. 
TABLE I

Mean and Percentile Values of HDL Cholesterol in Controls

\begin{tabular}{|c|c|c|c|c|c|c|}
\hline \multirow[b]{3}{*}{ Subject group } & & & \multicolumn{4}{|c|}{ HDL cholesterol } \\
\hline & \multicolumn{2}{|c|}{ Mean } & \multicolumn{2}{|c|}{ 5th percentile } & \multicolumn{2}{|c|}{ 10th percentile } \\
\hline & Females & Males & Females & Males & Females & Males \\
\hline & & & \multicolumn{4}{|c|}{ mg/dl } \\
\hline Hospital inpatients* & $52.2 \pm 0.7$ & $45.5 \pm 0.6$ & 29 & 24 & 33 & 28 \\
\hline Normolipidemic hospital inpatients $\$$ & $52.5 \pm 0.9$ & $46.0 \pm 0.9$ & 30 & 25 & 34 & 29 \\
\hline Normolipidemic volunteers $\S$ & $52.8 \pm 1.2$ & $46.9 \pm 1.8$ & 33 & 28 & 36 & 31 \\
\hline
\end{tabular}

* Females $(n=472)$; males $(n=517)$.

$\ddagger$ Females $(n=281)$; males $(n=280)$.

$\S$ Females $(n=100)$; males $(n=48)$.

tected in individuals predicted to be heterozygous for Tangier disease (Fig. 4). These lipids occur in histiocytes of the upper colonic lamina propria as sudanophilic intracytoplasmic droplets. Contrary to the fat present in submucosal fat cells, most of the histiocytic lipid deposits do not reduce osmium tetroxide indicative of the high degree of saturation of fatty acids in the stored lipids. Beneath or within the droplets there are birefringent crystalline inclusions which disappear upon heating to $60^{\circ} \mathrm{C}$ and reappear upon cooling.

In an inconsistent manner a few lipid droplets occurred in histiocytes of rectal mucosa biopsies obtained from controls. However, in no case were birefringent crystals detectable. The lipid-storing histiocytes may contain ceriod-type lipochrome granules exhibiting a weakly positive periodic acid-Schiff reaction and a vivid ultraviolet-autofluorescence. Contrary to the homozygous state, histiocytes in the deep lamina propria and smooth muscle cells are always void of lipid inclusions (Fig. 4).

HDL composition in heterozygotes. To evaluate the composition of HDL (Apo A-I, Apo A-II, and total cholesterol), a total of 12 heterozygous patients were selected from the 143 relatives of the propositi: seven obligate heterozygous patients (children and parents of propositi) and five presumed heterozygous patients (in whom abnormally low HDL cholesterol and Apo A-I values, as well as lipid storage in the rectal mucosa, has been documented). The results of the quantitative analyses of each of these patients and 10 controls are summarized in Table III and were obtained in the following ways: (a) Two-dimensional immunoelectrophoresis of fresh serum allows for the determination of the total quantities of $A$ apoproteins and their distribution among lipoproteins. As demonstrated in Fig. 5, the total quantity of HDL apoprotein was substantially reduced in heterozygous patients. A apoprotein antigenicity could be detected only in regular alpha-electrophoretic position excluding the possibility that major amounts of $A$ apoproteins in heterozygotes are associated with lipoproteins other than HDL. The ratio of Apo A-I to Apo A-II in the HDL of heterozygotes, as evaluated by area measurements of the immunoprecipitates obtained with monospecific antisera, was identical to that of control HDL contained in fresh serum. The results of quantitative analyses deduced from these immunoelectrophoresis experiments are listed in Table III. (b) Independent confirmation of the absolute quantities of $\mathrm{A}$ apoproteins and their ratio in the native sera of heterozygotes and controls was obtained by Laurell electroimmunoassay and doubleantibody radioimmunoassay of $\mathrm{A}$ apoproteins contained in Apo HDL (Table III). The results of these analyses were in close agreement with those obtained

TABLE II

Mean and Percentile Values of Serum Apo A-I in Controls

\begin{tabular}{|c|c|c|c|c|c|c|}
\hline \multirow[b]{3}{*}{ Subject group } & & & \multicolumn{4}{|c|}{ Apoprotein A-I } \\
\hline & \multicolumn{2}{|c|}{ Mean } & \multicolumn{2}{|c|}{ 5th percentile } & \multicolumn{2}{|c|}{ 10th percentile } \\
\hline & Females & Males & Females & Males & Females & Males \\
\hline & & & \multicolumn{4}{|c|}{$m g / d l$} \\
\hline Normolipidemic volunteers* & $121 \pm 7.1$ & $110 \pm 6.4$ & 82 & 77 & 86 & 83 \\
\hline
\end{tabular}

*Females $(n=100)$; males $(n=48)$. 


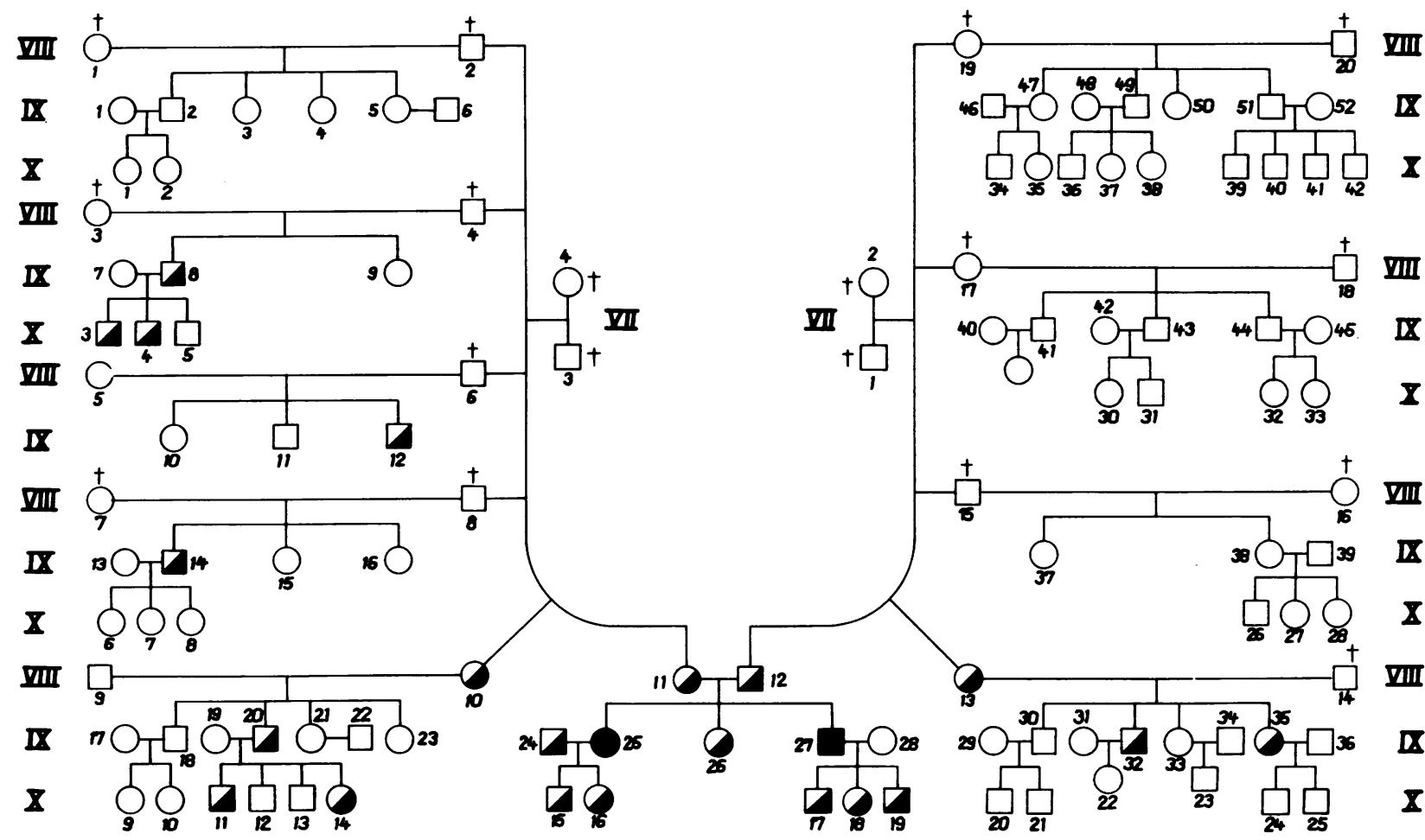

FIGURE 3 Pedigree of the S. family. Heterozygous patients were identified according to 5 th percentile Apo A-I cutoffs as indicated in Table II and Fig. 2. Symbols: homozygous - female (O),

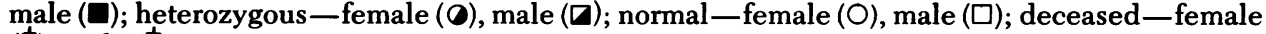
(ठ), male (古).

by two-dimensional immunoelectrophoresis. (c) Agarose gel chromatography of the $d=1.006-1.21 \mathrm{~g} / \mathrm{ml}$ $\mathrm{KBr}$ lipoproteins reveals a regular elution profile of HDL obtained from heterozygous patients (Fig. 6). The total amount of HDL protein, as measured by ultraviolet absorption of column fractions at $280 \mathrm{~nm}$, was substantially reduced in all heterozygous patients. HDL column fractions were concentrated and qualitatively analyzed for their apoprotein composition by SDS polyacrylamide electrophoresis (not shown). The gel-electrophoresis pattern did not provide evidence for an abnormal distribution of $\mathbf{A}$ apoproteins; in particular, an A-II lipoprotein particle, present in the plasma of homozygous patients (2), could not be detected in any of the heterozygous patients studied. $(d)$ Electron microscopy of negatively stained HDL fractions isolated from heterozygous patients by ultracentrifugation $(d=1.063-1.21 \mathrm{~g} / \mathrm{ml} \mathrm{KBr})$ did not reveal any morphological abnormality or preponderance of particles of smaller or larger size (80-150 $\AA$ diameter) (not shown).

Two aspects of the plasma lipoproteins in heterozygotes deserve mention: first, in contrast to homozygous patients who demonstrated low LDL concentrations and an abnormal LDL cholesterol/triglyceride ratio
(1/3), both the absolute amounts of LDL and its composition were normal in heterozygous patients; and second, the particle spectrum extending from VLDL to LDL in the serum of homozygous patients (Fig. 6) could not be observed in the serum of heterozygous patients.

\section{DISCUSSION}

The familial nature of Tangier disease was recognized in the early reports by Fredrickson et al. $(20,21)$. These authors have provided evidence that major clinical manifestations (splenomegaly, hepatomegaly, lymphadenopathy, peripheral neuropathy, corneal alterations, low plasma cholesterol) occur in the homozygous genotype, and that heterozygotes, although asymptomatic clinically, can be detected by a decrease in plasma HDL cholesterol concentrations. The biochemical conclusions drawn from these earlier studies, however, were limited since HDL was thought to contain only one apoprotein. Later observations have indicated that normal HDL contains two major apoproteins (Apo A-I and Apo A-II), and that these apoproteins have a function in lipid metabolism (Apo A-I as activator protein of lecithin-cholesterol acyltransferase) in addition to their ability to solubilize and transport lipids (22). More 

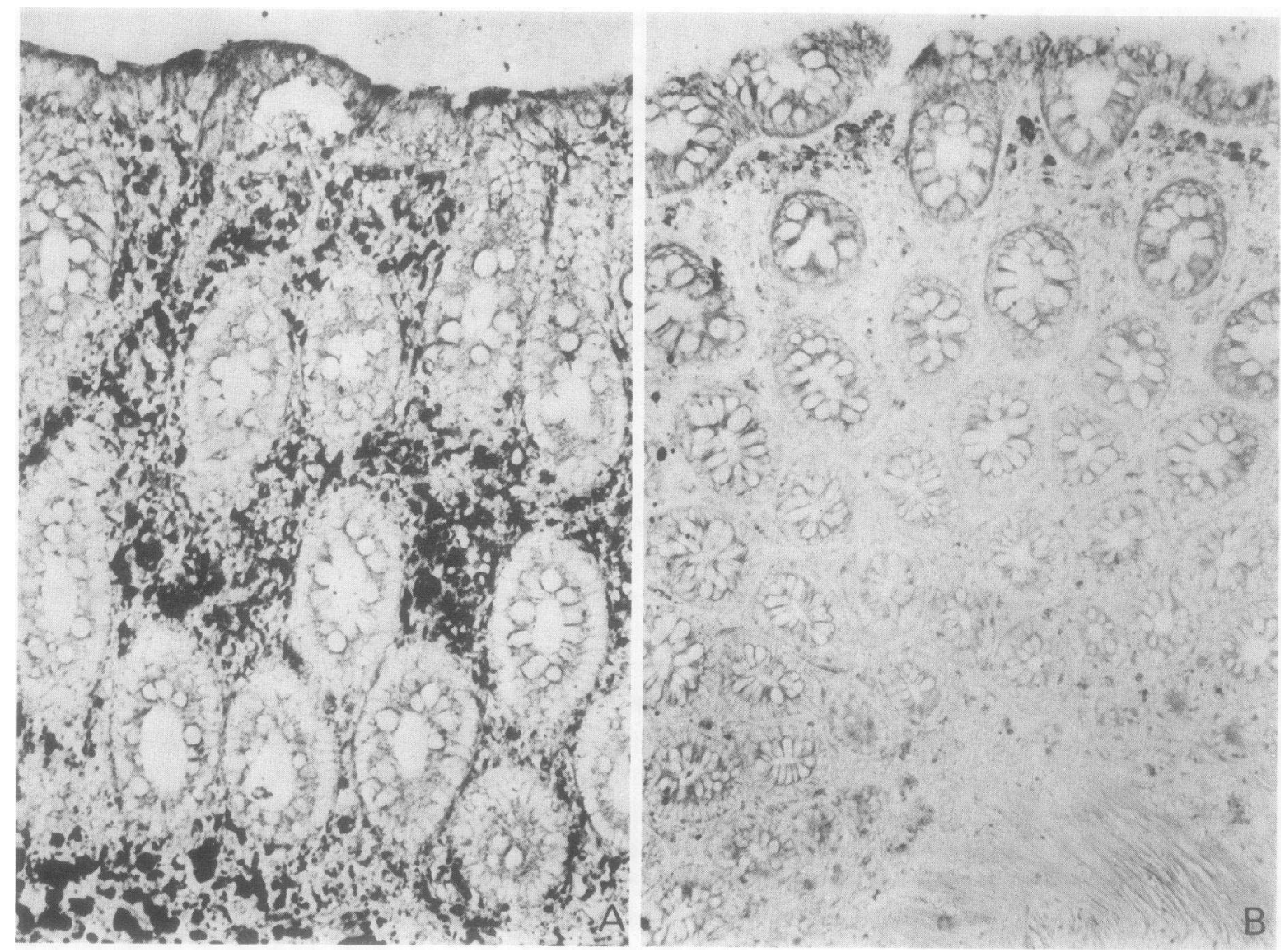

Figure 4 Cryostat sections of rectal mucosa stained by Sudan black B. (A) Patient J. S., homozygous for Tangier disease; abundant lipid storage in histiocytes throughout mucosal stroma. (B) Patient M. G., heterozygous for Tangier disease; lipid storage in histiocytes located almost exclusively beneath the epithelial surface.

recent evidence derived from immunochemical and physicochemical analyses of HDL suggests that Apo A-I and Apo A-II in HDL occur in a molar ratio of approximately two-to-one $(1,23)$, which is possibly an essential requirement for the structural integrity of these lipoproteins.

The results of the present investigation establish that this molar stoichiometry is maintained in the HDL of heterozygous patients, although the absolute quantities of this lipoprotein and its constituent $\mathrm{A}$ apoproteins are reduced to approximately $50 \%$ of normal. As confirmed by two-dimensional immunoelectrophoresis of serum, radioimmunoassay of Apo HDL, and gel chromatography of lipoproteins obtained from patients heterozygous for Tangier disease, the A apoproteins are mostly confined to HDL. Despite an intensive search, no abnormal lipoproteins, as previously described for homozygous patients (2), could be detected in the heterozygous carrier.

In these studies, the existing abnormally low HDL cholesterol and $A$ apoprotein deficiency, in conjunction with histological evidence of lipid storage in the rectal mucosa, have been used as parameters for provisional detection of family members heterozygous for Tangier disease. It is apparent that in the absence of a genetic marker or an abnormal lipoprotein in circulation, patients heterozygous for Tangier disease cannot be identified with certainty in the general population on the basis of low HDL cholesterol or Apo A-I deficiency alone. The studies clearly reveal that cutoff points, below which $5 \%$ of control values are found, may serve only as arbitrary limits, and that HDL cholesterol values or serum A apoprotein concentrations in heterozygotes may fall outside and within the normal range. In addition, the question to what extent age, sex-linked factors, nutrition, or environmental factors may have influenced HDL levels in heterozygotes cannot be ascertained at present. A decreased HDL level may also be encountered in other genetic disorders (abetalipoproteinemia, familial hyperchylomicronemia, and familial lecithin-cholesterol acyltransferase deficiency) $(10,24,25)$ and in certain metabolic alterations (carbo- 
TABLE III

HDL Composition in Patients Heterozygous for Tangier Disease

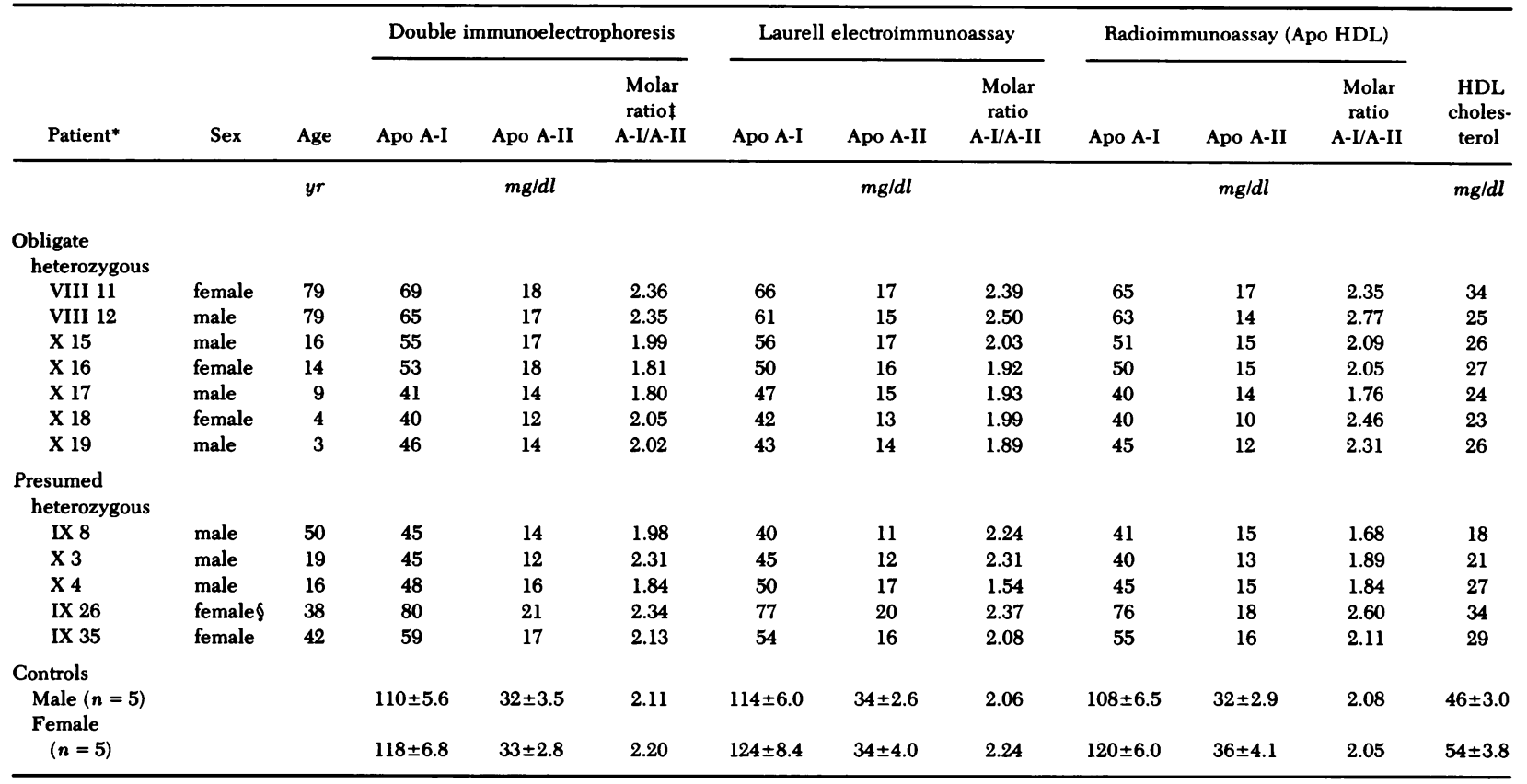

* See pedigree of family (Fig. 3).

† Assuming that 28.300 and 17.400 are mol wt for Apo A-I and Apo A-II, respectively.

$\$$ Patient on oral contraceptives.

hydrate feeding, malnutrition, and hypertriglyceridemia) (26). These examples of secondary HDL deficiency, the precise origin of which is not understood in most cases, amplify the observation that the segregation of heterozygotes in Tangier disease on the basis of lipoprotein or apoprotein determination in serum is most difficult to undertake. The finding, however, that HDL deficiency in Tangier disease is associated with lipid storage in the rectal mucosa and possibly other tissues may provide a useful index to monitor for heterozygous patients in the population.

There are certain lipid and lipoprotein abnormalities (fasting hyperchylomicronemia, hypertriglyceridemia, "broad-beta" band in agarose electrophoresis, and triglyceride-rich LDL) which have been observed in most patients homozygous for Tangier disease (19). In our studies, with the exception of mild hypertriglyceridemia in a few instances, none of these features could be detected in any of the heterozygous patients. This is good supporting evidence for the belief that the

Figure 5 Two-dimensional immunoelectrophoresis of serum obtained from two controls and two obligate heterozygous patients (M. G., R. S.). HDL antiserum was employed for immunoprecipitation of $\mathrm{A}$ apoproteins contained in normal serum (A, B) and Tangier serum (heterozygotes, C, D). For details see Methods.

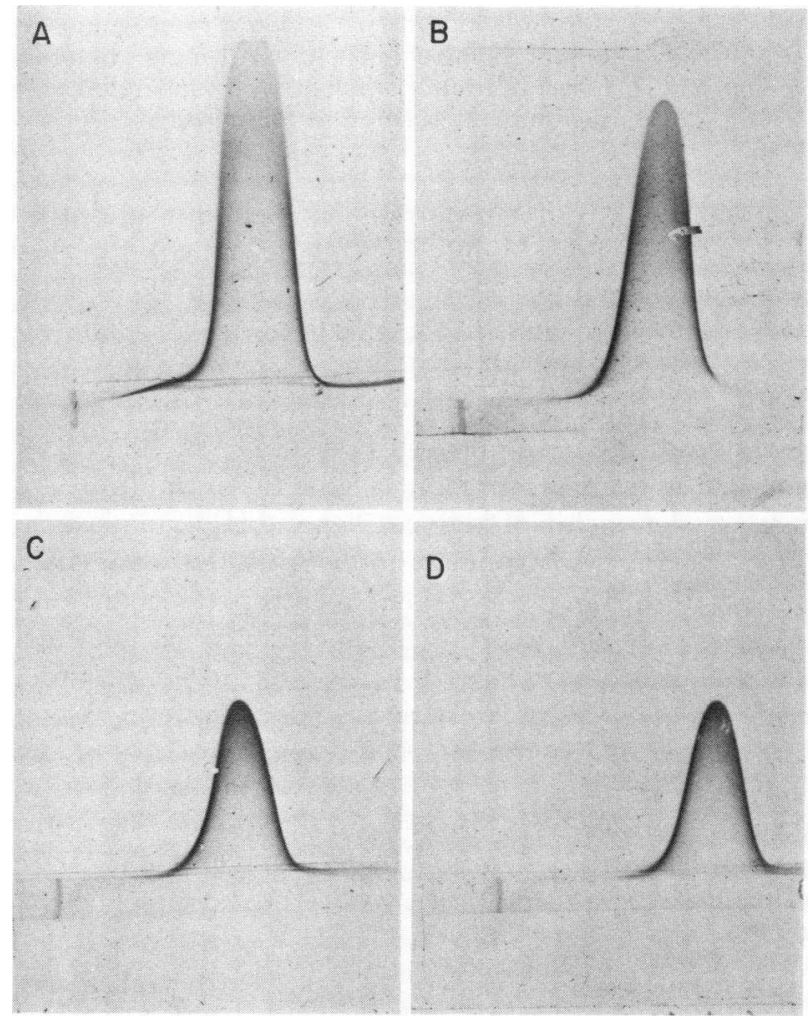




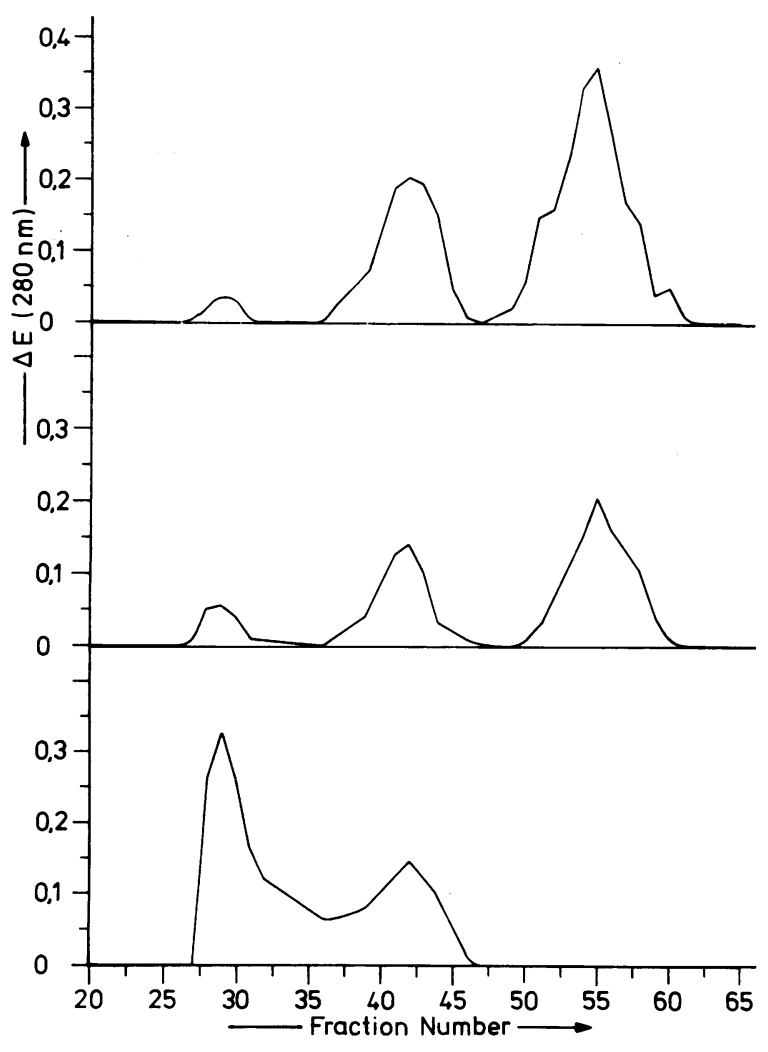

Figure 6 Agarose column elution profile of lipoproteins from control (upper), heterozygous (middle), and homozygous (lower) Tangier serum. Lipoproteins isolated from serum of patients E. G. (Tangier, homozygous), M. G. (Tangier, heterozygous), and a normolipidemic subject were separated according to the procedures described in Methods.

catabolism of triglyceride-rich lipoproteins and the formation of LDL are only secondarily affected in the homozygous patient as a consequence of complete HDL deficiency, and that in the heterozygote, half of the normal amount of HDL is sufficient to maintain regular lipoprotein interconversion. Nevertheless, the mild hypertriglyceridemia observed in some heterozygous patients may represent a genetic example of an inverse relationship of triglycerides and HDL in plasma.

In this context it appears noteworthy that extensive clinical studies in the two homozygous patients (42 and 46 years old) and two obligate heterozygous patients (parents of propositi; 79, 79 years old) did not provide evidence of coronary artery disease or peripheral vascular disease. ${ }^{3}$ Thus, genetic HDL deficiency may be an important exception to the general concept that subnormal levels of HDL are related to the risk of acquiring coronary artery disease $(15,27-30)$. There are several possible interpretations of HDL deficiency in

${ }^{3}$ Assmann, G., H-E. Schaefer, J. Zach, Th. Gheorghiu, and K. Oette. Unpublished observations.
Tangier disease, which may explain the findings in homozygous and heterozygous patients $(1,2)$. The observations made in this study, that heterozygotes have normal HDL in circulation, the total amount of which is reduced by approximately $50 \%$, and histochemically evident lipid storage in histocytes, might be explained as the result of a primary catabolic defect. It can be speculated that sequestration of normal HDL in reticuloendothelial tissues accounts for both lipid storage in histiocytes and low or depleted plasma HDL in patients affected with Tangier disease.

\section{ACKNOWLEDGMENTS}

The authors wish to thank Priv. Doz. Dr. Gheorghiu and Priv. Doz. Dr. Frotz, Innere Medizin, Kliniken der Universität Köln, for performing rectoscopy in several of our patients; cand. med. G. Hammer for assistance in pedigree analysis; and Miss M. Nyfeler for excellent technical assistance. We further appreciate the assistance of Dr. H. D. Helb in performing statistical analyses.

We are very grateful for the financial support from the Ministerium für Wissenschaft und Forschung, Nordrhein-Westfalen, West Germany.

\section{REFERENCES}

1. Assmann, G., E. Smootz, K. Adler, A. Capurso, and K. Oette. 1977. The lipoprotein abnormality in Tangier disease. Quantitation of A apoproteins. J. Clin. Invest. 59: 565-575.

2. Assmann, G., P. N. Herbert, D. S. Fredrickson, and T. Forte. 1977. Isolation and characterization of an abnormal high density lipoprotein in Tangier disease. J. Clin. Invest. 60: 242-252.

3. Gheorghiu, Th., G. Assmann, and H-E. Schaefer. 1976. Endoscopic findings in Tangier disease. Endoscopy. 8: $164-169$.

4. Schaefer, H-E., G. Assmann, and Th. Gheorghiu. 1976. Licht- und elektronenmikroskopische Untersuchungen zur Tangier Krankheit (sog. An-alpha-Lipoproteinämie). Verh. Dtsch. Ges. Pathol. 60: 473.

5. Eggstein, M., and F. H. Kreutz. 1966. Eine neue Bestimmung der Neutralfette im Blutserum und Gewebe. Klin. Wochenschr. 44: 262-267.

6. Stähler, F., E. Munz, and R. Kattermann. 1975. Enzymatische Bestimmung von Gesamt-Cholesterin im Serum. Dtsch. Med. Wochenschr. 100: 876-887.

7. Kostner, G. M. 1976. Enzymatic determination of cholesterol in high density lipoprotein fractions prepared by polyanion precipitation. Clin. Chem. 22: 695.

8. U. S. Department of Health, Education, and Welfare, National Institutes of Health. 1974. Lipid Research Clinics Program Manual. Laboratory Operations, Vol. 1. DHEW Publication No. (NIH) 75-628.

9. Laurell, C. B. 1972. Electroimmunoassay. Scand. J. Clin. Lab. Invest. 29(Suppl. 124): 21-37.

10. Lux, S. E., K. M. John, and H. B. Brewer, Jr. 1972. Isolation and characterization of apo LP-Gln-II (apo A-II), a plasma high density apolipoprotein containing two identical polypeptide chains. J. Biol. Chem. 247: 7510-7518.

11. Lowry, O. H., N. J. Rosebrough, A. L. Farr, and R. J. Randall. 1951. Protein measurement with the Folin phenol reagent. J. Biol. Chem. 193: 265-275.

12. Weber, K., and M. Osborn. 1969. The reliability of molecular weight determinations by dodecyl sulfate-polyacryla- 
mide gel electrophoresis. J. Biol. Chem. 244: 44064412.

13. Schaefer, H-E., and R. Fischer. 1970. Peroxidaseaktivität als Ursache der stabilen Sudanophilie in Granulozyten. Klin. Wochenschr. 48: 1424-1425.

14. Barka, T., and P. J. Anderson. 1962. Histochemical methods for acid phosphatase using hexazonium pararosaniline coupler. J. Histochem. Cytochem. 10: 741-753.

15. Albers, J. J., P. W. Wahl, V. G. Cabana, W. R. Hazzard, and J. J. Hoover. 1976. Quantitation of apolipoprotein A-I of human plasma high density lipoprotein. Metab. Clin. Exp. 25: 633-644.

16. Havel, R. J. 1957. Early effects of fat ingestion on lipids and lipoproteins of serum in man. J. Clin. Invest. 36: 848-854.

17. Fredrickson, D. S. 1964. The inheritance of high density lipoprotein deficiency (Tangier disease). J. Clin. Invest. 43: 228-236.

18. Havel, R. J., H. A. Eder, and J. H. Bragdon. 1955. The distribution and chemical composition of ultracentrifugally separated lipoproteins in human serum. J. Clin. Invest. 34: 1345-1353.

19. Fredrickson, D. S. 1966. Familial high density lipoprotein deficiency: Tangier disease. In The Metabolic Basis of Inherited Disease. J. B. Stanbury, J. B. Wyngaarden, and D. S. Fredrickson, editors. McGraw-Hill, Inc., New York. 2nd edition. 486-508.

20. Fredrickson, D. S., P. H. Altrocchi, L. V. Avioli, D. S. Goodman, and H. C. Goodman. 1961. Tangier disease. Ann. Intern. Med. 55: 1016-1031.

21. Hoffman, H. N., and D. S. Fredrickson. 1965. Tangier dis- ease (familial high density lipoprotein deficiency). Clinical and genetic features in two adults. Amer. J. Med. 39: 582-593.

22. Jackson, R. L., J. D. Morrisett, and A. M. Gotto, Jr. 1976. Lipoprotein structure and metabolism. Physiol. Rev. 56: 259-316.

23. Friedberg, S. J., and J. A. Reynolds. 1976. The molar ratio of the two major polypeptide components of human high density lipoprotein. J. Biol. Chem. 251: 4005-4009.

24. Alaupovic, P., W. J. McConathy, M. D. Curry, H. N. Magnani, H. Torsvik, K. Berg, and E. Gjone. 1974. Apolipoproteins and lipoprotein families in familial lecithincholesterol acyltransferase deficiency. Scand.J. Clin. Lab. Invest. 33(Suppl. 137): 83-87.

25. Assmann, G. 1976. High density lipoprotein abnormalities associated with disease. Fourth International Symposium on Atherosclerosis. Springer-Verlag, KG., Berlin. In press.

26. Levy, R. I., C. B. Blum, and E. J. Schaefer. 1976. The composition, structure and metabolism of high density lipoprotein. In Lipoprotein Metabolism. H. Greten, editor. Springer-Verlag, KG., Berlin. 56-60.

27. Miller, G. J., and N. E. Miller. 1975. Plasma-high-density-lipoprotein concentration and development of ischaemic heart-disese. Lancet. I: 16-19.

28. H. D. L., and C. H. D. 1976. Editorial. Lancet. II; 131132.

29. Berg, K., A-L. Borresen, M. H. Frick, G. Dahlen, and J. Stene. 1976. Serum- H. D. L. in atherosclerotic heartdisease. Lancet. II: 40-41.

30. Nikkilä, E. A. 1976. Serum high-density-lipoprotein and coronary heart disease. Lancet. II: 320 . (Abstr.) 